\title{
Characterisation of Natural Fibre Reinforcements and Composites
}

\author{
Richard K. Cullen, Mary Margaret Singh, and John Summerscales \\ Advanced Composites Manufacturing Centre, School of Marine Science and Engineering, Reynolds Building, \\ Plymouth University, Plymouth PL4 8AA, UK
}

Correspondence should be addressed to John Summerscales; jsummerscales@plymouth.ac.uk

Received 18 October 2013; Accepted 25 November 2013

Academic Editor: Masamichi Kawai

Copyright (C) 2013 Richard K. Cullen et al. This is an open access article distributed under the Creative Commons Attribution License, which permits unrestricted use, distribution, and reproduction in any medium, provided the original work is properly cited.

\begin{abstract}
Recent EU directives (e.g., ELV and WEEE) have caused some rethinking of the life cycle implications of fibre reinforced polymer matrix composites. Man-made reinforcement fibres have significant ecological implications. One alternative is the use of natural fibres as reinforcements. The principal candidates are bast (plant stem) fibres with flax, hemp, and jute as the current front runners. The work presented here will consider the characterisation of jute fibres and their composites. A novel technique is proposed for the measurement of fibre density. The new rule of mixtures, extended for noncircular cross-section natural fibres, is shown to provide a sensible estimate for the experimentally measured elastic modulus of the composite.
\end{abstract}

\section{Introduction}

There have been a number of recent reviews [1-9] of natural fibre reinforcements and their composites. Virk et al. [10] proposed an extension to the rule of mixtures (ROM) for the estimation of the Young's modulus of a composite with reinforcements of noncircular cross-section:

$$
E_{c}=\kappa \eta_{d} \eta_{l} \eta_{o} V_{f} E_{f}+V_{m} E_{m},
$$

where $E_{x}$ is the Young's modulus, $V_{x}$ is the volume fraction, $\kappa$ is the fibre area correction factor (FACF) [10], $\eta_{d}$ is the fibre diameter distribution factor (FDDF) [11], $\eta_{l}$ is the fibre length distribution factor (FLDF) [12], and $\eta_{0}$ is the fibre orientation distribution factor (FODF) [13] with subscript $c, f, m$, and $v$ being composite, fibre, isotropic matrix, and voids $\left(V_{f}+V_{m}+\right.$ $V_{v}=1$ ), respectively. For the case of hollow fibres, the voidage should be classified as that internal to the fibre (i.e., the lumen in natural fibres), $V_{i}$, and that external to the fibre, $V_{e}$, such that $V_{f}+V_{m}+\left(V_{i}+V_{e}\right)=1$. When the fibres are characterised taking into account the internal features, the internal voids are not expected to influence the mechanical properties of the composites. The separation of internal and external voids is equally applicable to man-made hollow fibres [14, 15]. For hollow fibres, it is then necessary to determine the density of the fibre material (primarily cellulose in natural fibres) and the volume fraction of the void within the fibre.

Typical values for each of these parameters would be

(i) $E_{f}=14-87 \mathrm{GPa}$ (bast natural fibres) [6], $\sim 70 \mathrm{GPa}$ (glass), $140 \mathrm{GPa}$ (aramid), or $210 \mathrm{GPa}$ (carbon),

(ii) $E_{m}=1-3 \mathrm{GPa}$ (polymers),

(iii) $V_{f}=0.1-0.3$ (random orientation), 0.3-0.6 (woven fabric), or 0.5-0.8 (unidirectional),

(iv) $\kappa=1.42$ (i.e., $2697 \mu \mathrm{m}^{2} / 1896 \mu \mathrm{m}^{2}$ ) for jute [10] as the factor compensates for the overestimate in the apparent cross-sectional area (CSA) when CSA is derived from an apparent diameter with the assumption of circular cross-section and is calculated as the ratio of apparent CSA/true CSA,

(v) $\eta_{d}=1$ for well-characterised fibres but $\neq 1$ where there is a dependence of the modulus on fibre diameter,

(vi) $\eta_{l}=$ from 0 (if significantly less than the critical length as defined by Cox shear-lag theory) to 1 (for continuous fibres),

(vii) $\eta_{o}=1 / 4$ (biaxial on the bias angle), $3 / 8$ (random in-plane), $1 / 2$ (biaxial parallel to the fibres), or 1 
(unidirectional parallel to the fibres) as determined by the Krenchel equation:

$$
\eta_{o}=\sum_{i=0^{\circ}}^{180^{\circ}} V_{f_{i}} \cos ^{4} \theta_{i} .
$$

The indicative materials data above should not be used for "design" purposes. Daniel and Ishai [16] have stated that the ROM can be used where the fibre is anisotropic with different properties in the axial and transverse (radial) directions and that the matrix is isotropic. A more complete treatment of this assumption is given by Gibson [17].

The determination of the parameters required for the rule of mixtures can be achieved in a variety of ways including the Grafil [18] and CRAG [19] Test Methods. The determination of the fibre volume fraction in a natural fibre reinforced composite is problematic. The fibres are hygroscopic and so may swell, and weight is a function of the moisture content. The density of the fibre should be quoted at a specific moisture content (or ambient relative humidity) or ideally plotted against moisture content. The absorption of liquid by the test specimen may complicate the determination of $V_{f}$ when natural fibres are under test. The determination of volume fraction of the composite will be dependent on the moisture level and any consequent swelling of fibres. A key issue in the characterisation of fibres and their composites is thus an accurate value for the density of the cellulosic material in the natural fibre. Subject to the above, the fibre volume fraction of composite materials may be obtained directly, or by use of the rule of mixtures for density, $\rho_{c}=V_{f} \rho_{f}+V_{m} \rho_{m}$, by one or more of the following methods:

(i) tow counting for unidirectional composites in an open-ended mould,

(ii) fabric areal weight in a moulding of known thickness,

(iii) direct weighing when no fibre is lost in the moulding process,

(iv) density gradient column,

(v) Archimedes principle using weight measurements in air and in water (or other fluids),

(vi) resin burn-off in an oven at $580-600^{\circ} \mathrm{C}$ : inappropriate for natural fibre composites,

(vii) thermogravimetric analysis (TGA),

(viii) chemical digestion,

(ix) optical microscopy, electron microscopy or X-ray tomography, and image analysis $[20,21]$.

More information, and references, for each of these techniques can be found in [7].

Facca et al. [22] found that standard micromechanics models for the prediction of the elastic properties of natural fibre composites had mixed success. This paper will consider a novel route to the accurate determination of the fibre density, and then examine the use of the extended rule of mixtures (1) to predict the tensile modulus of a jute fibre reinforced epoxy composite.

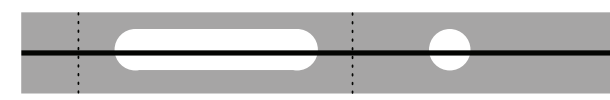

FIGURE 1: Schematic of the Grafil test card (grey) with the fibre (black) and the left aperture for tensile testing (50 mm gauge length) and the right aperture for microscopy (10 $\mathrm{mm}$ aperture).

\section{Experimental Methodology}

Jute fibre of unknown provenance (from the same batch as studied in references $[10,23]$ ) was chosen as the material for study. The fibre density was determined by Archimedes principle. Fibres were coiled into small bundles and dried at $60^{\circ} \mathrm{C}$ for $30 \mathrm{~min}$ and then immediately weighed in air on an AveryBerkel digital scale (serial number 59030902). The fibres were then suspended, immersed in the test fluid, and degassed in a vacuum chamber:

(i) in water (with Ilfotol as a wetting agent) at a vacuum level of -990 mbar,

(ii) in acetone at a vacuum level of -500 mbar (vacuum level limited to prevent sudden boiling).

When all the bundles had sunk to the base of the container and no gas could be seen escaping from the bundle, the chamber was slowly vented to atmosphere and the bundle was weighed on a Stanton Instruments analogue scale (serial number 19635). The fibre density, $\rho_{f}$, was calculated using the equation in CRAG method 800 :

$$
\rho_{f}=\frac{a \rho_{x}}{(a-b)},
$$

where $a$ is the mass in air, $b$ is the apparent mass in the fluid, and $\rho_{x}$ is the density of the fluid at the temperature of the test. The densities determined for the jute fibres were

$$
\begin{gathered}
\rho_{f}=1669 \pm 37 \mathrm{~kg} \cdot \mathrm{m}^{-3} \text { in water/Ilfotol at } 22.4^{\circ} \mathrm{C}, \\
\rho_{f}=1652 \pm 37 \mathrm{~kg} \cdot \mathrm{m}^{-3} \text { in acetone at } 20.3^{\circ} \mathrm{C} .
\end{gathered}
$$

Note that these densities are higher than those normally quoted in the natural fibre literature $\left(\sim 1525 \mathrm{~kg} \cdot \mathrm{m}^{-3}\right.$ [6] for flax, hemp, and jute), but the latter are rarely determined from degassed fibres. After removal from the respective fluids, the fibres were allowed to equilibrate with the ambient humidity for thirty minutes and then weighed in air. Absorption of $4 \%$ moisture resulted in a density of $1570 \pm 43 \mathrm{~kg} \cdot \mathrm{m}^{-3}$ which is comparable with the highest values quoted in the literature for natural fibres.

The tensile properties of single fibres from jute sliver were obtained using Grafil Test Method 101.13 on an Instron 1026 universal testing machine (serial number H2709) with an Instron 2511-101 $500 \mathrm{~g}$ load cell (serial number UK953, calibrated with $50 \mathrm{~g}$ weights) at a cross-head speed of $0.5 \mathrm{~mm} / \mathrm{min}$. The fibre cross-sectional area (CSA) was obtained by embedding fibres from the microscopy area of the test card (Figure 1) along the principal axis of a cylindrical block of epoxy resin. The cast cylinder was split parallel to the 

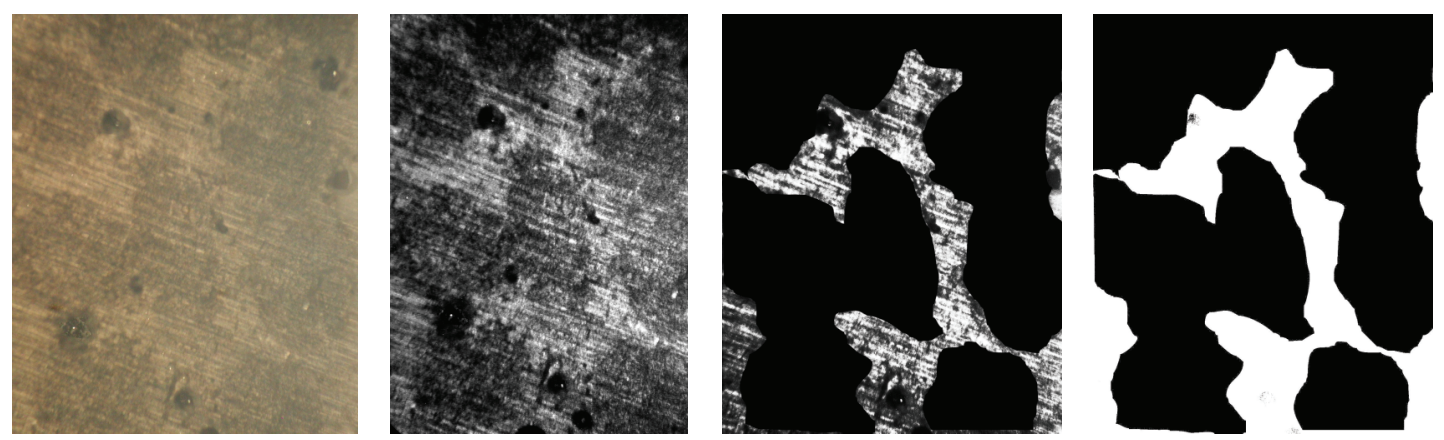

Figure 2: A typical sequence of optical microscope images from the raw image through processing to the binary format for analysis. Each yarn has a diameter of $\sim 600 \mu \mathrm{m}$ with individual fibres in the range $42-64 \mu \mathrm{m}$.

flat surfaces to provide two representative sections separated by $3-4 \mathrm{~mm}$ (the width of the slitting saw blade) in respect of their position along the fibre. Digital images of each crosssection were obtained using a Nikon 9953.2 megapixel digital camera from a Leica DMIRB inverted optical transmission microscope and the CSA was determined using ImageJ software (http://rsb.info.nih.gov/ij/) referenced to images of a standard $10000 \mu \mathrm{m}$ graticule with $10 \mu \mathrm{m}$ divisions.

To manufacture the composite, $506 \mathrm{~g} / \mathrm{m}$ (506 ktex) jute spun yarn was wound onto a lathe-mounted spool to produce an aligned quasi-unidirectional reinforcement. This reinforcement was transferred to the mould on a wire frame designed to maintain a slight tension on the fibres. The composite was manufactured by resin infusion under flexible tooling with a flow medium (RIFT II) [24] after allowing two hours under vacuum for the fibre to degas at $9.7 \mathrm{mbar}$ absolute (Digitron $8025 \mathrm{P}$ vacuum gauge) before infusion with SP Systems Prime 20 epoxy resin system (target mix ratio = $100 \mathrm{~g}$ batch $090730 \mathrm{resin} / 25 \mathrm{~g}$ batch 089017 slow hardener). Postcure was $3 \mathrm{~h}$ at $25^{\circ} \mathrm{C}$, ramp to $60^{\circ} \mathrm{C}$ at $+0.5^{\circ} \mathrm{C} / \mathrm{min}$, $16 \mathrm{~h}$ at $60^{\circ} \mathrm{C}$, and $\mathrm{ramp}$ at $-0.5^{\circ} \mathrm{C} / \mathrm{min}$ to return to ambient temperature.

Mechanical properties of the jute yarn composites were obtained according to ISO 527-5 for tensile modulus and strength on an Instron 1175 universal testing machine (serial number $\mathrm{H} 0525$ ) with a $100 \mathrm{kN}$ load cell (serial number UK195) at a cross-head speed of $2 \mathrm{~mm} / \mathrm{min}$ with an Instron $50 \mathrm{~mm}$ gauge length extensometer (serial number 2630113 No 77 ) and $\pm 45^{\circ}$ glass/epoxy end tabs. Interlaminar shear strengths (ILSS) were obtained according to ISO EN 14130:1998 on an Instron 4301 universal testing machine (serial number H0718) with an Instron $5 \mathrm{kN}$ load cell (serial number UK3191) at a cross-head speed of $2 \mathrm{~mm} / \mathrm{min}$.

To determine the fibre volume fraction, samples were prepared for optical microscopy by a coarse polish with 400 grit abrasive to give good contrast. Polishing with fine grit results in a smooth surface free of scratches but having significantly lower contrast. Digital images were obtained using an Olympus BX60M optical microscope (serial number 5M0733) with an Olympus 30303.2 megapixel camera, manipulated with Photoshop CS to enhance the contrast so that boundaries could be identified and the image was converted to a binary format (Figure 2). Image analysis was then undertaken using ImageJ to determine the black/white ratio and hence derive the respective fibre volume fractions. Knowledge of the true fibre cross-sectional area allows both $\kappa$ and $\eta_{d}$ to be set to unity. A similar technique was used to determine the void volume fraction.

\section{Results}

The results from experimental mechanical testing of the fibres (from nine samples) were tensile modulus $E_{f}=$ $27.7 \pm 13.8 \mathrm{GPa}$, tensile strength $\sigma_{f}^{\prime}=430 \pm 248 \mathrm{MPa}$, and elongation at break $\varepsilon_{f}^{\prime}=1.44 \pm 0.43 \%$. The coefficients of variation $(\mathrm{CoV})$ for these data were $49.9 \%, 57.7 \%$, and $29.5 \%$, respectively, confirming the findings of Virk et al. [23] that failure strain is a more reliable design criterion than strength.

The results from experimental mechanical testing of the composites (from four samples with valid failure modes) were $E_{c}=10.0 \pm 0.7 \mathrm{GPa}, \sigma_{c}^{\prime}=132 \pm 11 \mathrm{MPa}$, and $\varepsilon_{c}^{\prime}=1.37 \pm$ $0.9 \%$. The interlaminar shear strength (ILSS) experimental results (from 16 samples with valid failure modes) were 14.2 \pm 2.5 MPa: a value consistent with those for composites with reasonable fibre/matrix interface bond strength and hence an indication that the assumption of well-bonded fibres is valid for the proposed model.

The FACF $(\kappa)$ and FDDF $\left(\eta_{d}\right)$ were taken to be unity. Fibre lengths were determined by deconstruction of a one metre length of the 506 ktex spun yarn. Over half the fibres by weight had lengths in the range $100-180 \mathrm{~mm}$ with $<12 \%$ by weight being $<50 \mathrm{~mm}$ and no fibres $>280 \mathrm{~mm}$ long. It is therefore assumed reasonable to take FLDF $\left(\eta_{l}\right)=1$. The twist angle of the spun yarn was $\sim 30^{\circ}$ (ten measurements along $1 \mathrm{~m}$ of yarn), so the FODF $\left(\eta_{o}\right)=0.563$ using the Krenchel FODF (2). The fibre $\left(V_{f}\right)$ and void $\left(V_{e}\right)$ volume fractions from optical microscopy were $61.2 \pm 1.1 \%$ and $3.6 \pm 3.3 \%$, respectively. Using (1) with tensile moduli from the single fibre experiments and $E_{m}=3.2 \mathrm{GPa}$ (SP Systems data), the predicted modulus was $10.8 \mathrm{GPa}$. This value is just $8 \%$ higher than the value measured experimentally (and comparable with the experimental $\mathrm{CoV}$ of $7 \%$ for the composite modulus).

\section{Summary}

This paper has presented a novel method for the determination of the density of a natural fibre reinforcement using 
Archimedes principle in combination with vacuum degassing of the sample. The new rule of mixtures (ROM) for composites reinforced with non-circular CSA fibres was introduced. ROM has been shown to provide sensible estimate of the elastic modulus of natural fibre composites produced from jute fibres where the fibres have been well characterised. The strain to failure was found to vary less than strength and modulus as previously reported by Virk et al.

\section{Acknowledgments}

This paper is based on experimental data in an invited presentation "The determination of the fibre volume fraction in natural fibre composites" at the Exploratory Workshop on Environmentally Friendly Composites (EnviroComp), European Science Foundation Physical and Engineering Sciences Committee, University of Warwick-Coventry, April 2021,2004 . The same paper was also presented at Universiti Putra Malaysia on September 22, 2004. The authors wish to acknowledge Terry Richards for assistance with mechanical testing and the preparation of samples for optical microscopy and Peter Bond for assistance with image analysis.

\section{References}

[1] N. P. J. Dissanayake and J. Summerscales, "Life cycle assessment for natural fibre composites," in Green Composites from Natural Resources, V. K. Thakur, Ed., chapter 8, pp. 157-186, Taylor \& Francis, Amsterdam, The Netherlands, 2014, http://www .crcpress.com/product/isbn/9781466570696.

[2] C. Hill and M. Hughes, "Natural fibre reinforced composites opportunities and challenges," Journal of Biobased Materials and Bioenergy, vol. 4, no. 2, pp. 148-158, 2010.

[3] M. P. Ho, H. Wang, J. H. Lee et al., "Critical factors on manufacturing processes of natural fibre composites," Composites B, vol. 43, no. 8, pp. 3549-3562, 2012.

[4] G. Koronis, A. Silva, and M. Fontul, "Green composites: a review of adequate materials for automotive applications," Composites $B$, vol. 44, no. 1, pp. 120-127, 2013.

[5] D. U. Shah, "Developing plant fibre composites for structural applications by optimising composite parameters: a critical review," Journal of Materials Science, vol. 48, no. 18, pp. 60836107, 2013.

[6] J. Summerscales, N. P. J. Dissanayake, W. Hall, and A. S. Virk, "A review of bast fibres and their composites-part 1: fibres as reinforcements," Composites A, vol. 41, no. 10, pp. 1329-1335, 2010.

[7] J. Summerscales, N. Dissanayake, W. Hall, and A. S. Virk, "A review of bast fibres and their composites-part 2: composites," Composites A, vol. 41, no. 10, pp. 1336-1344, 2010.

[8] J. Summerscales, A. S. Virk, and W. Hall, "A review of bast fibres and their composites-part 3: modelling," Composites A, vol. 44, no. 1, pp. 132-139, 2013.

[9] J. Summerscales and S. Grove, "Manufacturing methods for natural fibre composites," in Natural Fibre Composites: Materials, Processes and Properties, A. Hodzic and R. Shanks, Eds., chapter 7, pp. 176-215, Woodhead, Cambridge, UK, 2014, http://www.woodheadpublishing.com/en/book.aspx?bookID= 2620.
[10] A. S. Virk, W. Hall, and J. Summerscales, "Modulus and strength prediction for natural fibre composites," Materials Science and Technology, vol. 28, no. 7, pp. 864-871, 2012.

[11] J. Summerscales, W. Hall, and A. S. Virk, "A fibre diameter distribution factor (FDDF) for natural fibre composites," Journal of Materials Science, vol. 46, no. 17, pp. 5875-5880, 2011.

[12] H. L. Cox, "The elasticity and strength of paper and other fibrous materials," The British Journal of Applied Physics, vol. 3, no. 3, pp. 72-79, 1952.

[13] H. Krenchel, Fibre Reinforcement, Akademisk Forlag, Copenhagen, Denmark, 1964.

[14] M. Hucker, I. Bond, S. Bleay, and S. Haq, "Experimental evaluation of unidirectional hollow glass fibre/epoxy composites under compressive loading," Composites A, vol. 34, no. 10, pp. 927-932, 2003.

[15] M. Hucker, I. Bond, S. Bleay, and S. Haq, "Investigation into the behaviour of hollow glass fibre bundles under compressive loading," Composites A, vol. 34, no. 11, pp. 1045-1052, 2003.

[16] I. M. Daniel and O. Ishai, Engineering Mechanics of Composite Materials, Oxford University Press, New York, NY, USA, 2nd edition, 2005.

[17] R. F. Gibson, Principles of Composite Material Mechanics, McGraw-Hill, New York, NY, USA, 1994.

[18] Grafil Test Methods, (reference 000.05), Courtaulds Limited, Coventry, UK, 1980.

[19] P. T. Curtis, "CRAG test methods for the measurement of the engineering properties of fibre reinforced plastics," Royal Aircraft Establishment Technical Report RAE-TR-88-012, 1988.

[20] F. J. Guild and J. Summerscales, "Microstructural image analysis applied to fibre composite materials: a review," Composites, vol. 24, no. 5, pp. 383-393, 1993.

[21] J. Summerscales, Ed., Microstructural Characterisation of FibreReinforced Composites, Woodhead, Cambridge, UK; CRC Press, Boca Raton, Fla, USA, 1998.

[22] A. G. Facca, M. T. Kortschot, and N. Yan, "Predicting the elastic modulus of natural fibre reinforced thermoplastics," Composites A, vol. 37, no. 10, pp. 1660-1671, 2006.

[23] A. S. Virk, W. Hall, and J. Summerscales, "Failure strain as the key design criterion for fracture of natural fibre composites," Composites Science and Technology, vol. 70, no. 6, pp. 995-999, 2010.

[24] J. Summerscales and T. J. Searle, "Low-pressure (vacuum infusion) techniques for moulding large composite structures," Proceedings of the Institution of Mechanical Engineers L, vol. 219, no. 1, pp. 45-58, 2005. 

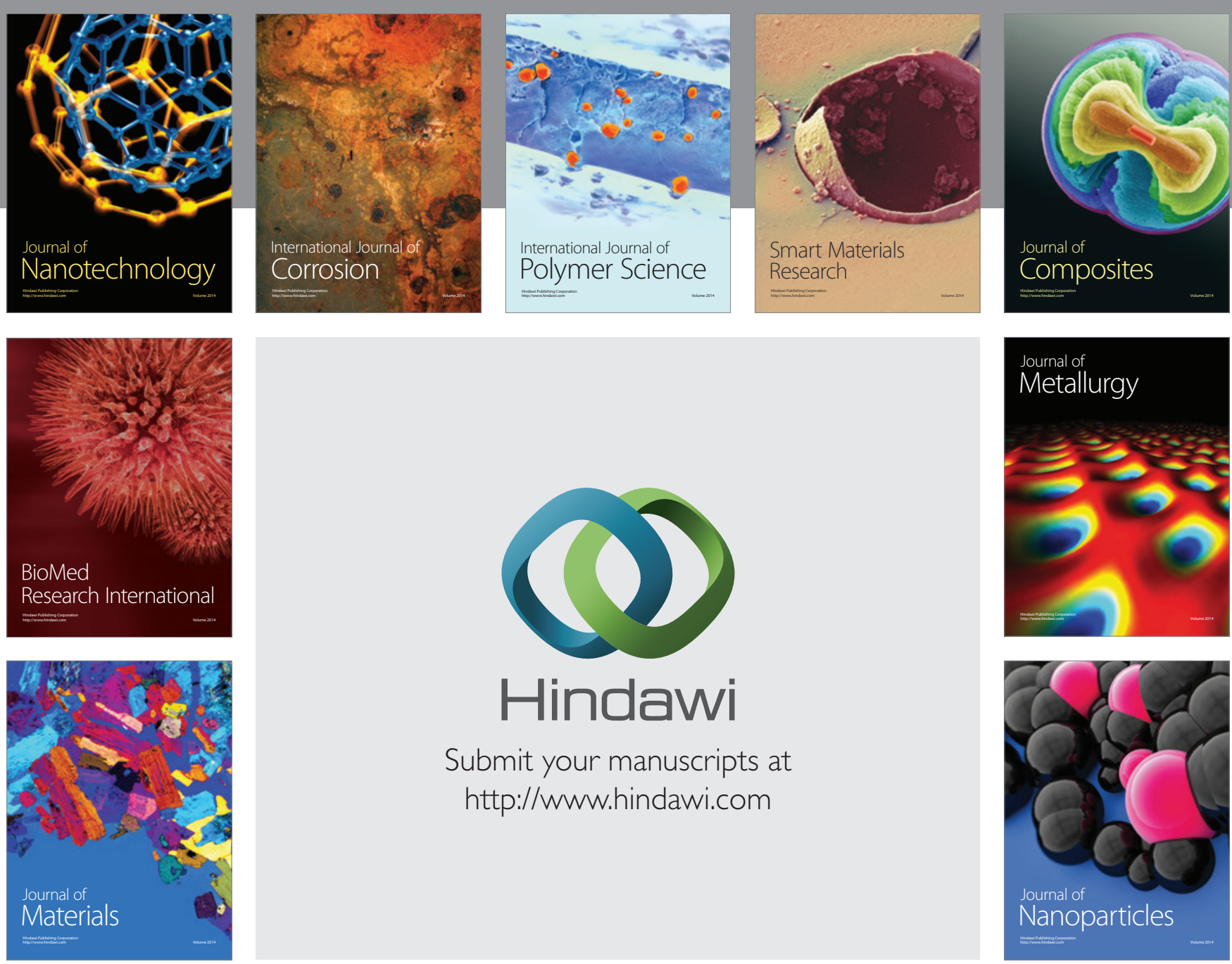

Submit your manuscripts at http://www.hindawi.com
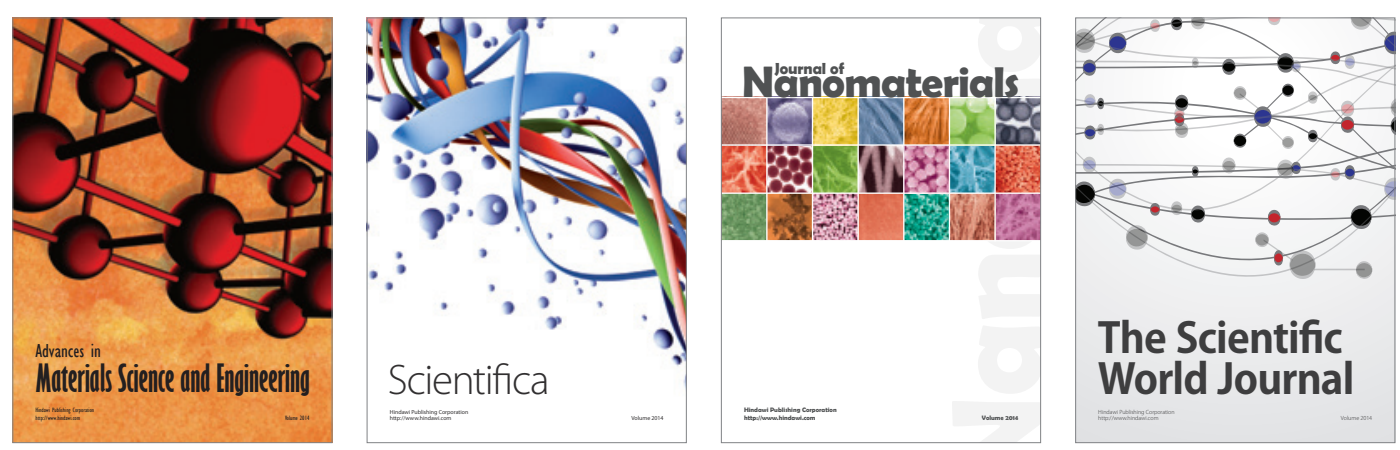

\section{The Scientific World Journal}
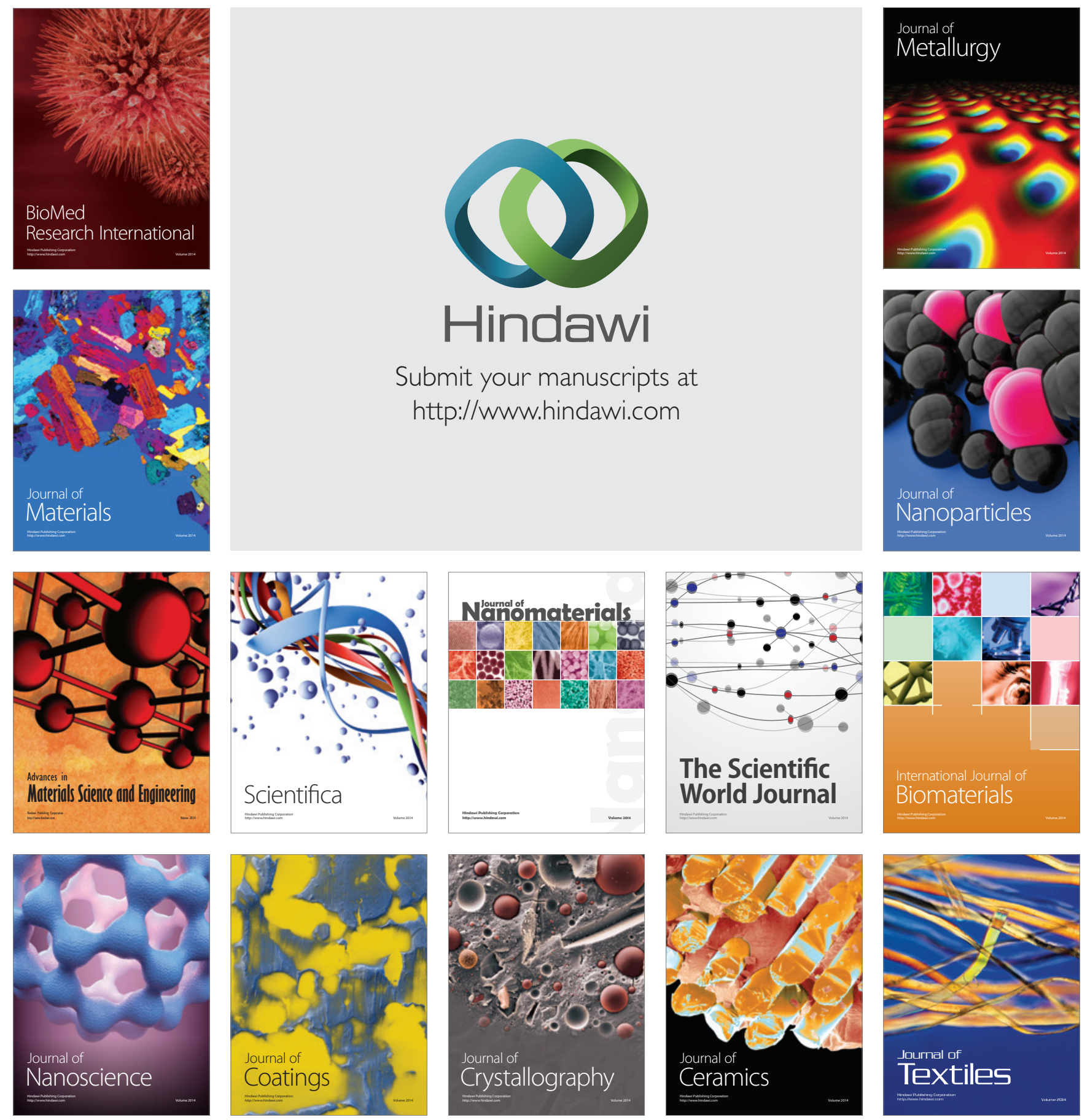